\title{
Determination of minimum CFRP pre-stress levels for fatigue crack prevention in retrofitted metallic beams
}

\author{
E. Ghafoori ${ }^{\mathrm{a}, \mathrm{d}, *}$, M. Motavalli ${ }^{\mathrm{a}}$, A. Nussbaumer ${ }^{\mathrm{b}}$, A. Herwig ${ }^{\mathrm{a}}$, G.S. Prinz ${ }^{\mathrm{c}}$, M. Fontana $^{\mathrm{d}}$ \\ ${ }^{a}$ Empa, Swiss Federal Laboratories for Materials Science and Technology, Structural Engineering Research Laboratory, Dübendorf, Switzerland \\ ${ }^{\mathrm{b}}$ EPFL, Swiss Federal Institute of Technology Lausanne, Steel Structure Laboratory (ICOM), Lausanne, Switzerland \\ ${ }^{\mathrm{C}}$ Department of Civil Engineering, University of Arkansas, Fayetteville, AR, USA \\ ${ }^{\mathrm{d}}$ ETHZ, Swiss Federal Institute of Technology Zürich, Institute of Structural Engineering (IBK), Zürich, Switzerland
}

\section{A R T I C L E I N F O}

\section{Article history:}

Received 3 April 2014

Revised 27 September 2014

Accepted 11 November 2014

\section{Keywords:}

Fatigue damage prevention

Mean stress influence

Constant life diagram (CLD)

Fatigue crack

Metallic beams

Pre-stressed carbon fiber reinforced

polymer (CFRP)

Strengthening

Steel

\begin{abstract}
A B S T R A C T
The majority of fatigue strengthening studies focus on reducing propagation rates of existing cracks, ignoring the crack initiation stage. Many existing metallic bridge members however do not contain existing cracks, but rather are nearing their design fatigue life. Limited research exists on the prevention of crack initiation using carbon fiber reinforced polymer (CFRP) materials. In this paper, constant life diagrams (CLDs) are used to determine the minimum level of CFRP pre-stress required to indefinitely extend the fatigue life of existing metallic beams. It is shown that by applying a compressive force to an existing fatigue-susceptible detail using pre-stressed CFRP plates, the mean stress level can be reduced such that the detail is shifted from the 'finite life' regime to the 'infinite life' regime. The proposed fatigue strengthening approach is advantageous particularly when the stress history from the prior traffic loadings is not known. To validate the proposed method, a pre-stressed un-bonded CFRP reinforcement system is introduced and tested on four metallic beams. The proposed un-bonded CFRP system is advantageous over traditional bonded CFRP systems as it can be applied to rough or obstructed surfaces (surfaces containing rivet heads or corrosion pitting for example). Additionally, the new un-bonded CFRP system offers a fast on-site installation (no glue and surface preparation are required) and an adaptive pre-stress level. Experimental results show that strengthening using pre-stressed CFRP plates are capable of shifting the working stresses from a finite fatigue-life zone to an infinite fatigue-life zone preventing crack initiation. Although according to many structural standards, the stress range is the main parameter that affects the fatigue life of a metallic detail, the results of this study clearly show that the mean stress level also plays a significant rule in the detail fatigue life. Based on the proposed CLD approach in this paper, the combined effects of the stress range and mean stress level can be taken into account for prediction of fatigue life of metallic members.
\end{abstract}

(c) 2014 Elsevier Ltd. All rights reserved.

\section{Introduction}

When a structural element experiences repeated cyclic loads, accumulated fatigue damage can ultimately lead to cracks which progress until complete fracture. The loading time prior to this complete fracture is considered the elements 'life time', $t_{t o t}$, and is considered as the sum of three distinct time intervals: the time for crack initiation, $t_{i}$, the time for stable crack propagation, $t_{p}$, and the time for fast crack propagation, $t_{d}$. The latter, $t_{d}$, is very short and is often neglected, thus $t_{\text {tot }}=t_{i}+t_{p}$. For structural metals,

\footnotetext{
* Corresponding author at: Empa, Swiss Federal Laboratories for Materials Science and Technology, Structural Engineering Research Laboratory, Dübendorf, Switzerland. Tel.: +4158765 4935; fax: +4158765 4455 .

E-mail address: elyas.ghafoori@empa.ch (E. Ghafoori).
}

the contribution of $t_{i}$ is much higher than $t_{p}$ (often reaching $80 \%$ of $t_{\text {tot }}$ or more).

It is important to distinguish between the crack initiation and crack propagation periods, because the parameters that influence the duration of each period are different. Surface conditions, for example, have an important influence on the duration of the initiation time period, but have insignificant effect on the crack growth period. In the crack initiation period, cyclic slip due to cyclic loadings results in crack nucleations followed by some microcrack growth and coalescence. The sizes of the microcracks in the beginning of the initiation period are on the order of a single grain and are not visible with the naked eye. Note that the process of crack initiation begins only when the applied cyclic stress is above the material fatigue limit, which depends on the stress range and the mean stress level. Microcrack growth typically turns into one 


\section{Nomenclature}

CLD constant life diagram

CFRP carbon fiber reinforced polymer

$R \quad$ stress ratio

$S_{a} \quad$ alternating strength

$S_{m} \quad$ midrange strength

$S_{e}^{\prime} \quad$ fatigue endurance limit of rotary-beam test specimen

$S_{e} \quad$ fatigue endurance limit in geometry and condition of use

$N \quad$ total no. of cycles to failure

$n_{b s}, n_{a s}$ applied no. of cycles 'before' and 'after' strengthening

$n_{r} \quad$ number of rivets in a line

$n \quad$ factor of safety

D overall accumulated damage

$A_{0.95 \sigma} \quad$ area of stressed at $95 \%$

$T_{c} \quad$ temperature in degree Celsius

$k_{t} \quad$ stress-concentration factor (SCF) $k_{f} \quad$ fatigue SCF

$q \quad$ notch sensitivity parameter

$\sqrt{a} \quad$ Neuber constant

$r \quad$ radius of the notch

$\sigma^{0} \quad$ nominal stress

$\sigma^{\infty} \quad$ stress far from hole

$\sigma^{h} \quad$ maximum stress at hole location

NDT non-destructive testing

$k_{\text {bearing }}$ SCF due to bearing effect of rivet shank

$k_{\text {hole }} \quad$ SCF due to a center hole in a plate

$h, A_{m}, I_{m}$ height, area and inertia of metallic beam section

$e \quad$ eccentricity between CFRP plate and beam neutral plane

$F \quad$ load applied by each hydraulic actuator

$F_{\text {pre }} \quad$ CFRP pre-stress force to prevent crack initiation

$R_{a} \quad$ surface roughness primary visible macrocrack, which is the beginning of the stable crack growth period. The crack initiation period is assumed to be completed when the propagation of the microcracks do not anymore depend on the material surface conditions [1]. This paper focuses on the crack initiation period $\left(t_{i}\right)$ and presents a method that is capable of lengthening this time period.

Fatigue retrofits made from carbon fiber reinforced polymer (CFRP) materials offer a promising solution for extending the total life time, $t_{t o t}$, of the structural metallic members. Many old metallic bridges still in operation are subjected to ever-increasing traffic loads which affect the remaining fatigue life by reducing the crack initiation period, $t_{i}$ [2]. Rather than replacing the entire bridge or member, municipalities often seek for retrofit solutions that can extend member fatigue life. CFRP materials have been used for many retrofit solutions in past decades due to their high strength-to-weight ratio, high corrosion resistance and excellent fatigue performance. By adding a pre-stress to the CFRP material, a larger portion of the material strength is used, resulting in higher yielding and ultimate load capacity in strengthened elements (e.g., $[3,4]$ ). Existing literature related to fatigue strengthening of metallic members have shown the superior performance of CFRPstrengthened members (e.g., [5-13]); however, the majority of these studies use an artificial initial crack, thereby neglecting the time required for completing the crack initiation period, $t_{i}$. With the inclusion of an artificial crack, the CFRP material only acts to lengthen the time for stable crack propagation, $t_{p}$, by reducing the stress intensity factor at the crack tip. In this paper, a method based on the constant life diagram (CLD) is proposed for predicting the minimum pre-stress level required to prevent fatigue crack initiation (i.e., $t_{i}=$ infinity) in metallic members. The validity of the proposed model is examined using laboratory fatigue experiments.

Flexural stiffening methods for structural members, using prestressed strings or cables, have been commonly used in construction for many structure types. For example, [14,15] present research on the flexural behavior of steel beams strengthened by pre-stressed steel tendons/cables. In this paper, a pre-stressed un-bonded reinforcement (PUR) system, with friction-based clamps, is introduced and tested. The main advantage of the proposed PUR system compared to the traditional method (using steel cables) is that it uses the CFRP laminates instead of steel tendons/ cables. CFRP laminates are much lighter than steel cables, which makes the process of on-site application easier. Furthermore, CFRP laminates have excellent fatigue and corrosion resistance and offer a wide range of Young's modulus ranging from less than $160 \mathrm{GPa}$ to more than $500 \mathrm{GPa}$, with ultimate strength up to around $4000 \mathrm{MPa}$.
Although the majority of CFRP-strengthened steel members have used glue to bond the laminates to the steel (e.g., [9,16-18]), it has been shown that the environmental conditions such as elevated or subzero temperatures, ultraviolet light, moisture and water as well as dynamic loadings such as impacts, earthquakes and fatigue can significantly affect the performance of the CFRP-to-steel bonded joints [19]. Since the proposed PUR system in this paper is un-bonded, it is applicable to rough or obstructed metallic surfaces (e.g., riveted beams) and offers a fast on-site installation (no glue and no surface preparation are required). Due to un-bonded nature of the system, the level of pre-stress in the CFRP plates can be still adjusted after strengthening. Furthermore, the system can be also removed from the metallic member, if necessary, without any damage to the original structure. The presented trapezoidal PUR system in this paper has been used for fatigue strengthening of metallic girders of a 120-years-old railway riveted bridge in Switzerland [20].

\section{Background theory}

In general, two methods are used to assess the fatigue life of structures, the stress-life and strain-life methods. With each of these methods, the number of cycles to failure $(N)$ is estimated; however the applicability of each method varies based on high cycle fatigue life or low cycle fatigue regimes. Fatigue life with $N \leqslant 10^{3}$ cycles is normally considered as 'low cycle' fatigue while 'high-cycle' fatigue occurs when $N>10^{3}$ [21]. The stress-life method represents high-cycle applications adequately, is easily applied in design, and extensive data on various materials are available. The strain-life method is based on the true stress-strain behavior during localized yielding and is mainly applicable for low-cycle fatigue applications. Because the main concern in civiltype infrastructure is high-cycle fatigue (many applied service load cycles), the stress-life method is chosen for the design approach of the post-tensioning in this paper.

\subsection{Fatigue failure criteria}

It can be assumed that fluctuating stresses often take the form of a sinusoidal pattern. Maximum stress, $\sigma_{\max }$, minimum stress, $\sigma_{m i n}$, stress amplitude, $\sigma_{a}$, and stress midrange, $\sigma_{m}$, of sample stress histories are shown in Fig. 1, where $\sigma_{a}$ and $\sigma_{m}$ are given by:

$\sigma_{a}=\left|\frac{\sigma_{\max }-\sigma_{\min }}{2}\right|$, 


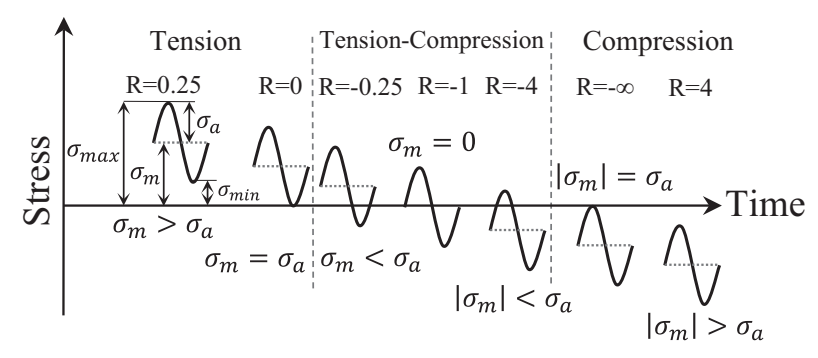

Fig. 1. Fluctuating stresses with various stress ratios.

and

$\sigma_{m}=\frac{\sigma_{\max }+\sigma_{\min }}{2}$

In addition, the stress ratio, $R$, is defined as:

$R=\frac{\sigma_{\min }}{\sigma_{\max }}$

Fig. 1 shows several fluctuating stresses with the same stress amplitude, $\sigma_{a}$, but different stress midranges, $\sigma_{m}$. As the stress midrange decreases, the fluctuating stress shifts from a full tension zone, to a tension-compression zone, and finally a full compression zone, thereby creating different $R$ ratios. Fig. 2 shows the stress amplitude, $\sigma_{a}$, versus the corresponding mean stress, $\sigma_{m}$, in the constant life diagram, CLD. In Fig. 2, $S_{y}, S_{u t}$ and $S_{e}$ are yield stress, ultimate tensile stress and the fatigue endurance limit, respectively. Note that the term fatigue endurance limit is equivalent to constant amplitude fatigue limit (CAFL) in civil engineering context. The fatigue endurance limit is typically determined as result of rotating-beam tests; however, the calculated fatigue endurance amplitude, $S_{e}$, is valid only for the stress ratio of $R=-1$ (i.e., $\sigma_{m}=0$, see Fig. 1). For the case of non-zero mean stress, the endurance amplitude is different and has to be calculated. Several models have been suggested to estimate the endurance amplitude for non-zero mean stress levels, as shown in Fig. 2. Goodman proposed a straight line through $\sigma_{a}=S_{e}$ and $\sigma_{m}=S_{u t}$, which is quite conservative for ductile metals but non-conservative for brittle metals. The criterion equation for the Goodman line is [21]:

$\frac{S_{a}}{S_{e}}+\frac{S_{m}}{S_{u t}}=1$,

where $S_{a}$ and $S_{m}$ are the alternating and midrange strength for any limiting point along the Goodman line. Gerber suggested a parabola for ductile metals passing through $\sigma_{a}=S_{e}$ and $\sigma_{m}=S_{u}$, and is written by [22]:

$\frac{S_{a}}{S_{e}}+\left(\frac{S_{m}}{S_{u t}}\right)^{2}=1$

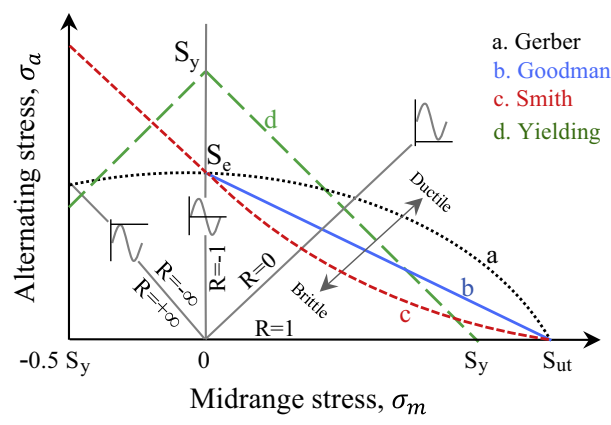

Fig. 2. Different CLDs to estimate the endurance limit of various metals as a function of the mean stress.
Smith represented a fatigue failure criterion that follows a concave upward curve in the first quadrant, as shown in Fig. 2. For the second quadrant, a straight line between $\left(0, S_{e}\right)$ and $\left(-S_{u t}, S_{u t}\right)$ is used. The Smith criterion is valid for most brittle metals [22] and is given by Eqs. (6.a) and (6.b).

$\frac{S_{a}}{S_{e}}=\frac{1-S_{m} / S_{u t}}{1+S_{m} / S_{u t}}, \quad 0 \leqslant S_{m} \leqslant S_{u t}$

$S_{a}=S_{e}+\left(\frac{S_{e}}{S_{u t}}-1\right) S_{m}, \quad-S_{u t} \leqslant S_{m} \leqslant 0$.

In Fig. 2, yield strength is plotted with two dashed straight lines and shows the first-cycle yielding criterion with the following relations for the first and second quadrants, respectively:

$S_{a}+S_{m}=S_{y}, \quad 0 \leqslant S_{m} \leqslant S_{y}$,

$S_{a}-S_{m}=S_{y}, \quad S_{y} \leqslant S_{m} \leqslant 0$.

\subsection{Modified endurance limit}

Results of lengthy fatigue tests [21] have shown that the fatigue endurance limit can be estimated by Eqs. (8.a) and (8.b).

$S_{e}^{\prime}=\left\{\begin{array}{ll}0.5 S_{u t}, & S_{u t} \leqslant 1400 \mathrm{MPa} \\ 700 \mathrm{MPa}, & S_{u t}>1400 \mathrm{MPa}\end{array}\right.$ for steel and wrought iron,

$S_{e}^{\prime}=\left\{\begin{array}{ll}0.4 S_{u t}, & S_{u t} \leqslant 400 \mathrm{MPa} \\ 160 \mathrm{MPa}, & S_{u t}>400 \mathrm{MPa}\end{array}\right.$ for cast iron.

The prime sign on $S_{e}^{\prime}$ in Eqs. (8.a) and (8.b) refer to rotating-beam specimens (i.e., $R=-1$ ) which were prepared very carefully and tested in laboratory conditions. The results of these tests cannot be readily used for details in civil engineering. Structural details often have geometrical imperfections and different surface preparations. Marin [23] has performed many different experiments to find out the influence of size, surface condition, loading and temperature on the fatigue endurance limit obtained from rotating beams. Marin could develop different parameters to quantify the influence of size, surface condition, loading and temperature through statistical analysis as:

$S_{e}=k_{a} k_{b} k_{c} k_{d} k_{e} S_{e}^{\prime}$

where $k_{a}, k_{b}, k_{c}, k_{d}$ and $k_{e}$ are modification factors for surface condition, size, load, temperature and reliability. $S_{e}$ is the endurance limit at the critical location of the member in condition and geometry of use, while $S_{e}^{\prime}$ is the rotary-beam test specimen endurance limit. The procedure to calculate the modification factors for the Marin equation of different beam types is described in Appendix A. Note that the results of rotating-beam specimens provide the endurance limits that are valid for $R=-1$, however using the CLD diagrams it is possible to estimate the endurance limits for any mean stress level. Although the modified Goodman criterion is relatively accurate, but it requires much knowledge (and computations) in order to calculate different coefficients in Marin's equation. The authors have suggested (see [20]) to use the Goodman formula when sufficient knowledge about the existing metallic girder exits, however when such information is lacking, the modified Johnson CLD criterion is recommended. Based on Johnson criterion, the endurance limit is estimated to be one third of the tensile strength $\left(S_{e}=S_{u t} / 3\right)$, and therefore there is no need to calculate the Marin's coefficients. More details about the Johnson criterion can be found in [20]. 


\subsection{Stress concentration and notch sensitivity factors}

Notches, holes, or defects within members can drastically affect the stress ranges applied to the structure during fatigue loading. Stress concentration factors are often used to account for such defects, holes, or notches. A stress-concentration factor, $k_{t}$, is defined as the ratio of the actual maximum stress $\sigma^{h}$ at the edge of hole to the nominal stress $\sigma^{0}$ along the section of the hole. Fig. 3 shows the stress-concentration factor (SCF) of a thin plate with a center hole loaded in tension, where $\sigma^{\infty}$ is the stress far from hole. The SCF depends only on the geometry of the sample and not the material properties. Nevertheless, it has been found that some materials are not sensitive to presence of a notch [21] and a reduced value of $k_{t}$ may be used. The maximum stress at the location of a hole, $\sigma^{h}$, is written by:

$\sigma^{h}=k_{f} \sigma^{\infty} \frac{w}{w-d}$,

where $k_{f}$ (which is a reduced value of $k_{t}$ ) is often called the fatigue $\mathrm{SCF}, w$ is the width of plate, $d$ is the diameter of hole and $\sigma^{\infty}$ is the stress level far from hole. Unlike $k_{t}, k_{f}$ depends on both geometry and material properties of the part and is defined by Eq. (11).

$k_{f}=1+q\left(k_{t}-1\right)$.

In Eq. (11), $q$ is the notch sensitivity parameter and is normally between zero and unity. Notch-sensitivity is defined as [24]:

$q=\frac{1}{1+\frac{\sqrt{a}}{\sqrt{r}}}$,

where $r$ is the radius of the notch and $\sqrt{a}$ is the Neuber constant, which depends on the material properties. The Neuber constant for steels are given in Table 1. Cast irons have very low notch sensitivity, values ranging from 0 to 0.2 depending on their tensile strength. For design purpose, it is recommended to use the conservative value of $q=0.2$ for all grades of cast irons [21]. A notch sensitivity of $q=1$ can also be used for wrought irons, which are more sensitive to notches. A more conservative and simple approach to find the fatigue SCF is to simply use $k_{f}=k_{t}$.

\section{Fatigue in metallic riveted bridges}

\subsection{Fatigue performance of structural cast iron, wrought iron and mild} steel

Cast iron contains $2.4-4 \%$ weight of carbon and is strong in compression but weak and brittle in tension. In contrast, wrought iron is a ductile material due to low quantity of carbon $(0.1-0.25 \%)$. It has a laminar non-homogenous microstructure with identical characteristics in compression and tension. Currently, mild (or

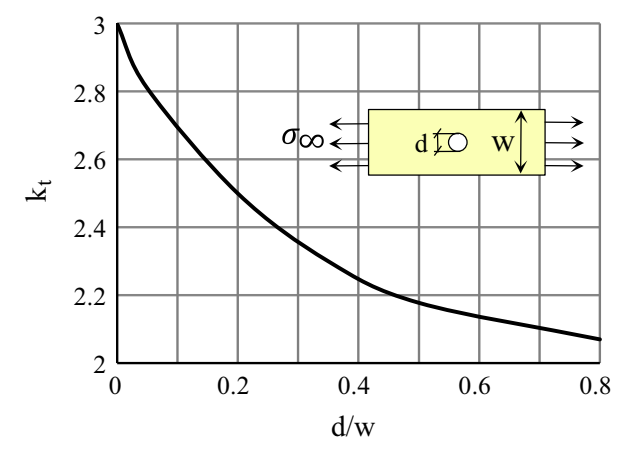

Fig. 3. SCF $\left(k_{t}=\frac{\sigma^{h}}{\sigma_{0}}\right)$ in a plate with a center hole in tension [17]. The nominal stress is $\sigma_{0}=\sigma_{\infty} \frac{w}{(w-d)}$.
Table 1

The Neuber constant for steels and wrought irons [20].

\begin{tabular}{ll}
\hline Notch type & $\sqrt{a(\mathrm{~mm})}, S_{u t}$ in MPa \\
\hline Transverse hole & $174 / S_{u t}$ \\
Shoulder & $139 / S_{u t}$ \\
Groove & $104 / S_{u t}$ \\
\hline
\end{tabular}

low carbon) steel is the most common structural steel with $0.05-0.3 \%$ carbon that results in a ductile behavior. Fatigue properties are dependent on material ductility. This difference can be seen clearly in the fatigue diagrams that were suggested in Section 2 (i.e., the Smith line for brittle and Gerber line for ductile materials). The fatigue failure criterion for brittle material (cast iron for example) is different significantly from ductile materials (such as wrought iron and mild steel) since in brittle materials: (1) yielding is not involved, (2) the ultimate compressive strength is larger than ultimate tensile strength and (3) they are more sensitive to mean stress level (see the Smith line in Fig. 2). For more ductile materials: (1) yielding shall be considered in design and (2) nearly identical compressive and tensile behavior is achieved. Note that based on the results of previous studies (e.g., [25-27]), wrought iron and mild steel have similar fatigue strength behavior. However, one problem related to fatigue strengthening of a wrought iron member is its interlaminar fatigue strength that is decreased substantially by delamination. Externally bonding CFRP to a wrought iron beam may be difficult due to this corrosion process and is not recommended until more research in this area has been performed [28].

\subsection{Fatigue performance of riveted connections}

The well known SCF for a plate with a center hole is shown in Fig. 3. When the ratio of the hole diameter to the plate width $(d / w)$ approaches 0 , the SCF tends to $3\left(k_{\text {hole }}=3\right)$, and for larger $d / w$ ratios, the SCF decreases. Riveted metallic bridge girders typically contain connections with many pre-tensioned rivets (or bolts) [2]; therefore, the SCF depends on the number of rivets in a line as well as the magnitude of pre-tensioning in the rivets. In this section, the fatigue strength of connections with and without pre-tensioned rivets is studied.

\subsubsection{Connection with pre-tensioned rivet}

In a connection with pre-tensioned rivets (or bolts), force is transmitted through frictional shear of the rivet-head contact surface, and by bearing of the rivet shank on the wall of rivet hole. When the rivet pre-tension level is high, friction between contact surfaces dominates, and for low (or no) pre-tension shank bearing dominates. The fatigue strength of a connection with one pre-tensioned rivet is much higher than the fatigue strength of a plate with one free center hole [29].

\subsubsection{Connection with non-pre-tensioned rivets}

As already mentioned, connections having one non-pre-tensioned rivet transfer a majority of the load through bearing of the rivet shank. The SCF of this joint type is equal to or larger than 5 (e.g., $k_{\text {bearing }}=5$ ) [30]. If the same joint has multiple rivets in a line, $n_{r}>1$, the effective SCF $\left(k_{\text {eff }}\right)$ is reduced [31] (see Eq. (13)):

$k_{\text {eff }}=\frac{k_{\text {bearing }}}{n_{r}}+\frac{n_{r}-1}{n_{r}} k_{\text {hole }}$.

This SCF reduction is due to flow of stresses that tend to distribute the force in plates among different rivets. As the number of rivets in a row increases, the fatigue strength of the riveted joint with and without pre-tension both approach to the fatigue strength of a plate with a center hole: 
$k_{\text {eff }}=\lim _{n_{r} \rightarrow \infty}\left(\frac{k_{\text {bearing }}}{n_{r}}+\frac{n_{r}-1}{n_{r}} k_{\text {hole }}\right)=k_{\text {hole }}$.

From this simplified model, it is concluded that for connections with non-pre-tensioned rivets, fatigue resistance increases with an increase in the number of rivet holes. In order to confirm this conclusion, several joints with various number of rivets along a row subjected to fatigue loading, as shown in Fig. 4, has been tested [31]. From Fig. 4, for more than four rivets in a line, the fatigue strength of joints with and without pre-tension is equal to that of a plate with a center hole.

Since riveted metallic bridge girders usually consist of connections with many rivets (more than 4 ) in a line, the design or verification of the girders in this study can be reasonably performed with the free hole assumption independent of any rivet pre-tension level.

\section{Minimum pre-stressing level to prevent fatigue crack}

The main idea in this type of strengthening is to apply a compressive force to an existing metallic detail such that the mean stress level is reduced and the life of the detail is increased to infinity. However, the required compressive force can be provided by means of traditional or advanced pre-stressing techniques. As an example for traditional pre-stressing techniques, galvanized greased high-density polyethylene (HDPE) sheathed strands can be used. As an advanced strengthening material, CFRP plates were used in this study for strengthening of steel beams, because they are light and have excellent fatigue and corrosion resistance. The strengthening elements shall be chosen to be as light as possible to have little effect on the structure dead weight. Note that any increase in the dead weight of the structure results in an increased mean stress level that is counterproductive to the strengthening method goal (i.e., reducing the mean stress level).

In this section, a method to approximate the minimum CFRP pre-stress level required to prevent fatigue crack initiation in an existing metallic member is suggested for brittle and ductile metallic girders. Note that the method used in this paper is only to prevent fatigue crack initiation. In the case when a crack has been already detected in the metallic member prior to strengthening, the model that has been suggested by Ghafoori et al. $[7,8]$ can be used. The model is based on fracture mechanics and can determine the CFRP pre-stress level required to arrest the fatigue crack growth of an existing crack. Using non-destructive testing (NDT) examinations it is possible to assess the state of damage in the structural elements. Therefore, bridge authorities can use the results of the NDT inspections to choose the right strengthening scheme.

\subsection{Brittle metals}

The Smith criterion described in Section 2 is recommended for design with brittle materials such as structural cast iron. Fig. 5

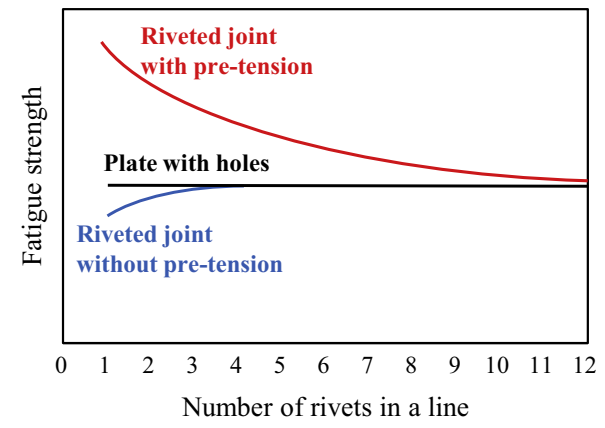

Fig. 4. Scheme of the fatigue strength of joints with multiple rivets along a line (based on the experimental results in [27]).

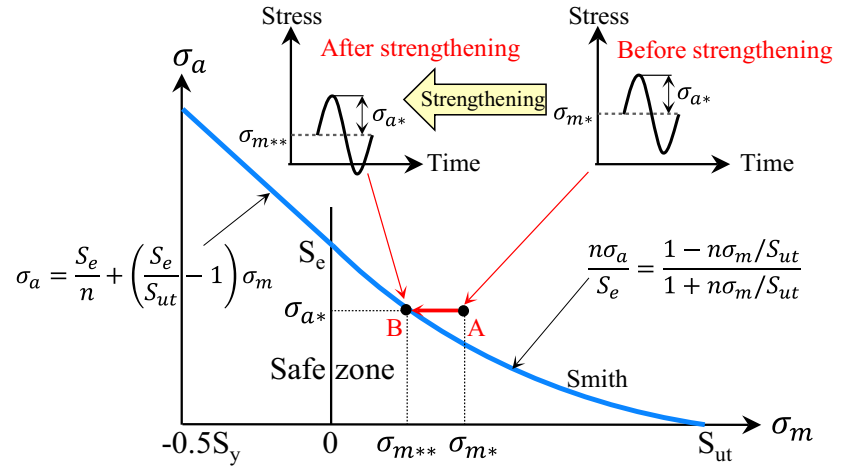

Fig. 5. Reducing the mean stress level from $\sigma_{a}^{*}$ to $\sigma_{a}^{* *}$ using pre-stressed CFRP plates such that the fatigue life prediction of the metallic detail is displaced form the finite to the infinite life region according to the Smith CLD criterion for brittle metals.

shows the Smith fatigue failure diagram. $n$ is the design safety factor. If the fatigue stresses remain outside of the Smith curve, the member has finite fatigue life, while any stress level inside this region has an infinite life.

Using pre-stressed CFRP plates, it may be possible to shift the stresses from the finite life zone to the infinite life zone. Point A in Fig. 5 refers to stress components in critical location of metallic member before strengthening and point B refers to the same location after strengthening. Because the stiffness of normal modulus CFRP is similar to that of steel, and CFRP plates are often thin in dimension, increase in beam stiffness due to CFRP strengthening is often negligible, along with the effect on beam stress amplitude. This is not the case for mean stress, which can be shifted by increasing the CFRP pre-stress. It is noted that if the pre-stress level is not sufficiently high to shift the stresses entirely into the safe region (somewhere along the line connecting points $A$ and $B$, see Fig. 5), the pre-stress still increases the life of the member to some extent; however, in this paper, the conservative aim is to reach an infinite fatigue life after strengthening. From Eq. (6.a), the Smith line in the first quadrant, becomes:

$\frac{n \sigma_{a}}{S_{e}}=\frac{1-n \sigma_{m} / S_{u t}}{1+n \sigma_{m} / S_{u t}}, \quad \sigma_{m} \geqslant 0$.

Note that $\sigma_{a}$ and $\sigma_{m}$ in Eq. (15), associated with the critical location of the part (e.g., at the hole location), are equal to $\sigma_{a}^{h}$ and $\sigma_{m}^{h}$ respectively, and shall be calculated using Eq. (10). Hereafter, to keep the notations simple, $\sigma_{a}$ and $\sigma_{m}$ are used in place of $\sigma_{a}^{h}$ and $\sigma_{m}^{h}$.

Consider a typical riveted girder, as shown in Fig. 6. Suppose the beam is subjected to cyclic loads resulting to fluctuating stresses of $\sigma_{a^{*}}$ and $\sigma_{m^{*}}$ at the rivet holes at the beam mid-span. The coordinate of stress components, shown with marker A in Fig. 5, is outside of fatigue safe zone specified by the Smith criterion. The magnitude of the required compressive stress in the beam bottom flange in order to shift the stresses into the safe zone is written by:

$\Delta \sigma_{m}=\sigma_{m^{*}}-\sigma_{m^{* *}}$

where $\sigma_{m}^{* *}$ is given by rewriting Eq. (15) in terms of mean stress level as:

$\sigma_{m}^{* *}=\frac{S_{e}-n \sigma_{a}^{*}}{n S_{e}+n^{2} \sigma_{a}^{*}} S_{u t}$,

Substituting Eq. (17) into Eq. (16) gives:

$\Delta \sigma_{m}=\sigma_{m^{*}}-\frac{S_{e}-n \sigma_{a^{*}}}{n S_{e}+n^{2} \sigma_{a^{*}}} S_{u t}$,

where $\Delta \sigma_{m}$ is the minimum required compressive stress in the metal. As mentioned earlier, if the medium modulus CFRP plates 

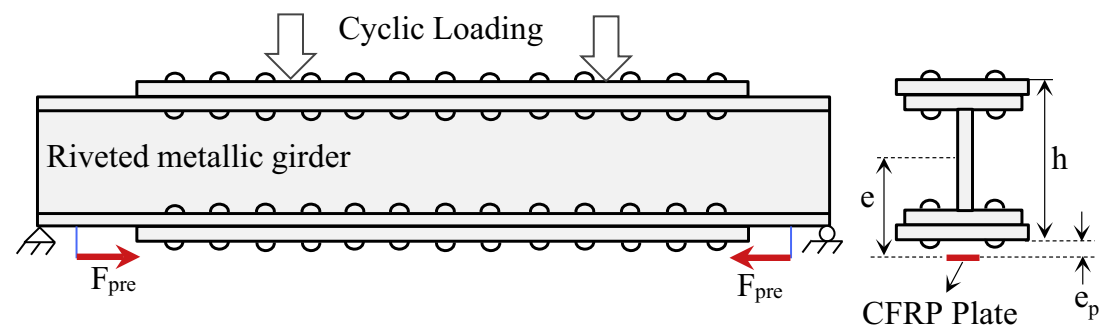

Fig. 6. A typical metallic riveted girder strengthened with pre-stressed un-bonded CFRP plates.

are used, the increase in stiffness of metallic member is negligible. Thus, to be more conservative, it is assumed that the stress in CFRP plate increases negligibly when the strengthened element is subjected to live loads. The minimum pre-stress force $\left(F_{\text {pre }}\right)$ in CFRP plate can be estimated by a simple cross-section analysis as:

$\Delta \sigma_{m}=\frac{e F_{p r e} h}{2 I_{m}}+\frac{F_{p r e}}{A_{m}}$,

where $h, A_{m}$ and $I_{m}$ are the height, the cross-sectional area and the moment of inertia of the metallic beam; $e$ is the eccentricity between CFRP plate and beam neutral axis, as shown in Fig. 6. In Fig. $6, e_{p}$ is the eccentricity between the CFRP plate and the bottom flange of the metallic beam. Rearranging Eq. (19) gives the minimum required pre-stress force in terms of stress range:

$F_{\text {pre }}=\frac{\Delta \sigma_{m}}{\frac{h e}{2 I_{m}}+\frac{1}{A_{m}}}$.

Substituting Eq. (18) into Eq. (20) gives:

$F_{\text {pre }}=\frac{\sigma_{m^{*}}+\frac{n \sigma_{a^{*}}-S_{e}}{n S_{e}+n^{2} \sigma_{a^{*}}} S_{u t}}{\frac{h e}{2 I_{m}}+\frac{1}{A_{m}}}$,

where $F_{\text {pre }}$ is the required pre-stress force in CFRP plate to have infinite fatigue life at the bottom flange of the metallic girder.

To determine the damage due to the variable amplitude (VA) fatigue loading, the Palmgren-Miner linear damage accumulation rule is used:

$D=\sum \frac{n_{i}}{N_{i}}=1$

where $N_{i}$ and $n_{i}$ are the number of cycles to failure and the applied number of cycles both at stress level $\sigma_{i}$, respectively. $D$ is the overall accumulated damage. The number of cycles to failure can be calculated with different methods (e.g., bilinear S-N curves with cut-off limit or the method in [21]). Note that in contrast to the PalmgrenMiner rule, there are several other damage accumulations theories (e.g., Manson's approach [32]) in which the order of application of the cyclic stresses are important. However, all these methods require more computational efforts, and at the end, they do not always improve the results of failure prediction [21]. In this regard, Collins says: "In spite of all the problems cited, the Palmgren linear damage rule is frequently used because of its simplicity and the experimental fact that other more complex damage theories do not always yield a significant improvement in failure prediction reliability" [33].

According to the Palmgren-Miner rule in Eq. (22), when accumulated damage is lower than unity, fatigue failure does not occur. Thus, the overall accumulated damage before and after strengthening shall remain lower than unity as:

$D=\sum \frac{n_{i}}{N_{i}}=\sum \frac{n_{i}^{b s}}{N_{i}^{b s}}+\sum \frac{n_{i}^{a s}}{N_{i}^{a s}=\infty}=\sum \frac{n_{i}^{b s}}{N_{i}^{b s}}<1$, where superscripts ' $b s$ ' and ' $a$ ' refer to 'before strengthening' and 'after strengthening', respectively. Since the strengthening is performed prior to completion of crack initiation phase (i.e., no visible macrocracks), and the applied level of pre-stress is sufficient to shift the stresses into the infinite fatigue life range, knowledge of prior traffic loading on the bridge is irrelevant. If the CFRP pre-stress level is not high enough to shift the stress components into the infinite fatigue life region (i.e., stresses remain somewhere along the line connecting points $A$ and $B$, see Fig. 5), a finite fatigue life is expected (i.e., $N_{a s} \neq \infty$ ) and the overall accumulated damage including the damages induced before and after strengthening $\left(N_{a s} \neq \infty \Rightarrow\right.$ $n_{a s} / N_{a s} \neq 0$ ) need to be checked. This requires knowledge of the load histories before and after strengthening.

\subsection{Ductile metals}

The Goodman line described in Section 2 was suggested for design of more ductile metals such as wrought iron and mild steel. Fig. 7 shows the modified Goodman guards against yielding. In order to estimate the required CFRP pre-stress to avoid fatigue crack in ductile members, the same procedure as was implemented for brittle metals in the last sub-section shall be used. The modified Goodman line in the first quadrant (before yielding) is written by:

$\frac{\sigma_{a}}{S_{e}}+\frac{\sigma_{m}}{S_{u t}}=\frac{1}{n}$.

The minimum required compressive stress in the critical location of metallic member is found in a similar way as Eq. (18) by:

$\Delta \sigma_{m}=\sigma_{m^{*}}+\frac{\sigma_{a^{*}}}{S_{e}} S_{u t}-\frac{S_{u t}}{n}$

Thus, the minimum pre-stress force $\left(F_{\text {pre }}\right)$ in CFRP plate is estimated as:

$F_{\text {pre }}=\frac{\sigma_{m^{*}}+\frac{\sigma_{a^{*}}}{S_{e}} S_{u t}-\frac{S_{u t}}{n}}{\frac{h e}{2 I_{m}}+\frac{1}{A_{m}}}$.

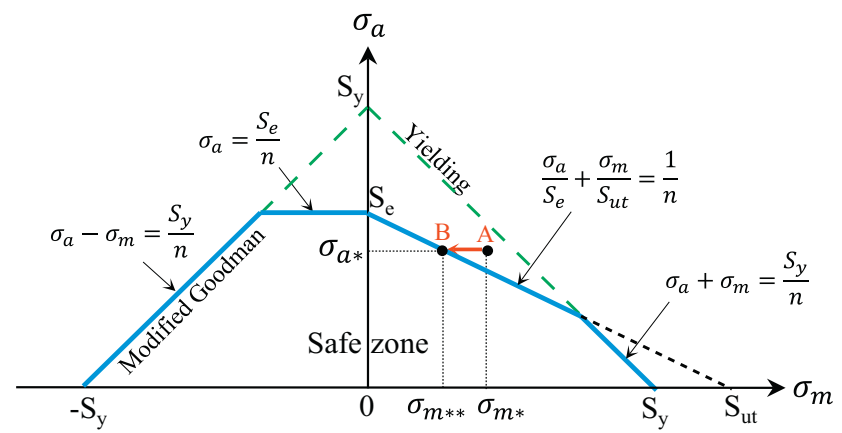

Fig. 7. Shifting stresses from the finite life regime to the infinite life regime using pre-stressed CFRP plates based on the modified Goodman criterion for ductile metals. 


\section{Experiments}

\subsection{Test set-up}

In order to examine the accuracy of the presented method, a total of four steel beams were subjected to cyclic loads. All beams were tested using a symmetric four-point bending set-up shown in Fig. 8a. As shown in Fig. 8a, the loading span is $1700 \mathrm{~mm}$ while the support span is $5000 \mathrm{~mm}$. A hydraulic testing machine (Pulsator P960), with $100 \mathrm{kN}$ actuator capacity and a force control system, was used to perform the cyclic loads. The loading frequency was chosen at $4.2 \mathrm{~Hz}$ for all specimens. Two small holes each with a diameter of $23 \mathrm{~mm}$ were drilled on bottom flange at mid-span (see Fig. 8b and c) to create stress concentrations to initiate fatigue cracks while additionally simulating the effect of rivet holes in riveted bridges.

Special attention was paid during drilling of the holes and quality control was ensured using NDT methods to verify the surface condition of the holes between specimens. The drilling procedure to create the holes was kept identical for all beam specimens. A surface roughness tester machine (Surftest-211 Mitutoyo) was used to measure the roughness of surface of the drilled holes. The surface of holes were polished up to a roughness $R_{a}=0.95-0.98 \mu \mathrm{m}$. Before beginning the tests, in order to ensure there is no defect or damage at the surface of holes, the Eddy Current testing system (Elotest B1) was used to inspect the samples. Eddy Current system works based on electromagnetic induction of circular coils and is often used to find flaws down to $0.5 \mathrm{~mm}$ in conductive metals.

\subsection{Pre-stressing technique}

The beams were strengthened using the trapezoidal PUR system, shown in Fig. 8a. The PUR system was developed at Empa and also patent [34]. Mechanical clamps hold three CFRP plates of $50 \mathrm{~mm}$ width and $1.2 \mathrm{~mm}$ thickness. The clamps work with friction eliminating the need to create holes in the specimen flange. The CFRP plates are gripped inside the mechanical clamps and are initially straight with no tension. As the eccentricity, $e_{p}$, between CFRP plates and steel beam increases (using a jack), the CFRP pre-stress level increases too (see Fig. 8a). Once the desired prestress level is achieved in the CFRP plates, the jack is replaced by a column. Note that during strengthening there is no external load on the beam $(F=0 \mathrm{kN})$. When the CFRP pre-stress increases, the compressive stress in steel bottom flange also increases. Details about the different elements of the PUR system including the mechanical clamps, the jacks and the columns are illustrated in $[20,35]$. This paper focuses on development of a method to quantify the required CFRP pre-stressing that can prevent fatigue cracking. Detailed FE modeling of the mechanical clamp and its contact with the I-beam can be found in [35].

The advantages of using the proposed PUR system are: (1) there is no need to glue CFRP to the member, (2) fast installation with no surface preparation, (3) easy applied pre-stress, (4) no traffic interruptions for bond curing, (5) no required damage to existing member (holes, gluing, grinding, etc.) using the friction clamps, (6) if the pre-stress level is reduced (due to relaxation or creep effects), it can be increased again, (7) the system can be uninstalled easily (if necessary) without any residual effect on the existing member.

A possible disadvantage of the trapezoidal PUR system is that it needs some space below the bridge (about $20-30 \mathrm{~cm}$ ). This reduces the headroom below the bridge that is need for the under bridge traffic. However, the PUR systems could have different configurations such as flat, triangle and trapezoidal. The decision about the type of PUR configuration depends on the ease of on-site application and efficiency of the system. In the flat PUR system, there is no need for columns, however a hydraulic actuator is required to pre-stress the CFRP plates. The hydraulic actuator pulls one end of the CFRP plates, while the other end is fixed to the bottom chord of the beam. Once the desired pre-stress force in CFRP plates is reached, the moving end of the CFRP plates is fixed to the beam chord.

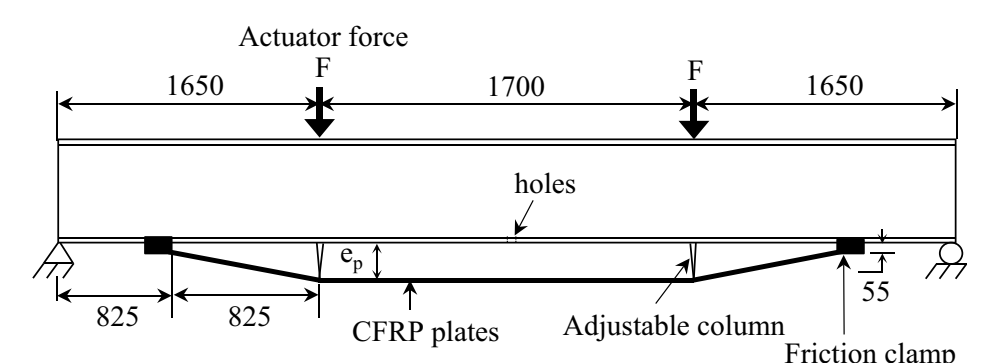

(a)

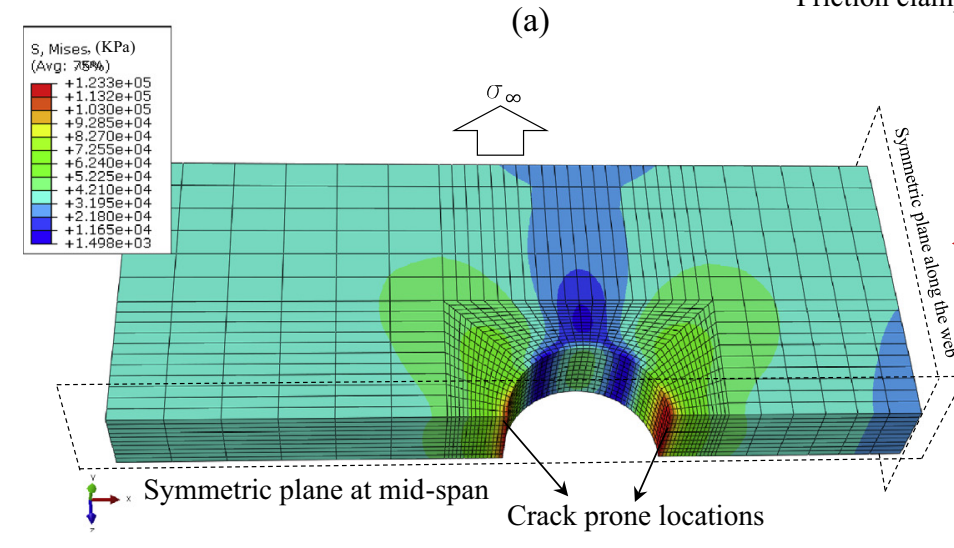

(d)

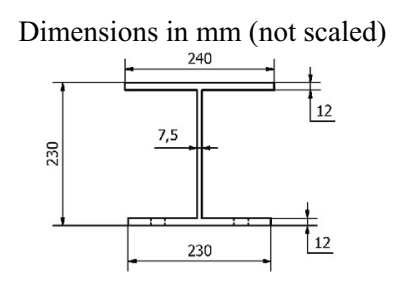

(b) the flange including the hole. 


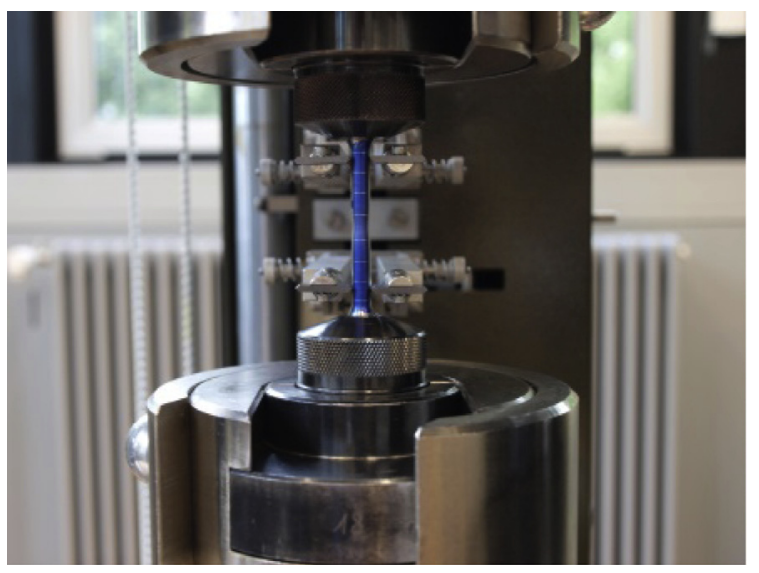

(b)

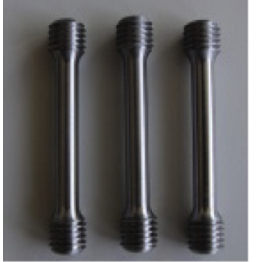

(a)

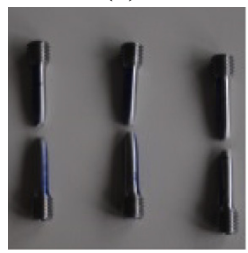

(c)

Fig. 9. (a) Steel samples cut from flange of one beam, (b) tensile test according to DIN 50125, and (c) fractured samples after the tensile test.

\subsection{Material}

All steel beam specimens were of type S355J0 (ST 52-3), with cross-sectional dimensions shown in Fig. 8b. All beam specimen materials were taken from the same steel production line to minimize the difference in behavior between production batches. In order to characterize the mechanical properties of the beams, tensile tests were performed on three samples cut from the flange of one specimen, as shown in Fig. 9. The tensile tests were designated according to DIN EN ISO 6892-1 with the specimen shape according to DIN 50125. Results show an average Young's modulus, yielding and ultimate strength of $209 \mathrm{GPa}, 417 \mathrm{MPa}$ and $562 \mathrm{MPa}$, respectively, with a relative standard deviation of less than $0.4 \%$. The CFRP plates were of type $150 / 2000$ (provided by the S\&P Company), with a width of $50 \mathrm{~mm}$ and a thickness of $1.2 \mathrm{~mm}$. Based on supplier tests, the CFRP plates had an average elastic modulus of 158.5 GPa and a tensile strength of $2714 \mathrm{MPa}$. The strain gauges used in the experiments were of type 6/120 LY16, with a $k$-factor of $2.06 \pm 1$ and an electric resistance of $120 \Omega \pm 0.35 \%$. One strain gauge was glued on the bottom flange of each steel beam (far from hole) (see Fig. 8c) and one strain gauge was glued at the middle of each CFRP plate.

\subsection{Fatigue parameters}

The modified Goodman fatigue failure criterion is used for the beam specimens given the higher ductility of the S355J0 (ST 52-3) steel. Conservative Marin factors (see Eq. (9)) were obtained through a conservative statistical approach, however the experiments in this work were performed under laboratory conditions and the specimens were polished at critical locations to smooth out any scratches. Thus, preliminary laboratory fatigue tests were performed to estimate the endurance limit of the beam specimens; with the endurance limit estimated as $S_{e}=256 \mathrm{MPa}$. The SCF due to holes with diameter $d=23 \mathrm{~mm}$ from Fig. 3 with a ratio of $d / w=23 / 115=0.2$ is 2.5 . To further investigate the stress distribution around the hole, ABAQUS finite element package was used to model a part of the bottom flange of beam including the hole, as shown in Fig. 8c. For computational efficiency, and based on symmetry, only one quarter of part of the flange was modeled. Twenty-node brick elements with reduced integration (C3D20R) were used. A refined mesh size of $1.2 \mathrm{~mm}$ was used for the area near the hole to accommodate the high stress gradient. The bottom flange was assumed in tension (see Fig. 8c and d). Material behavior obtained from tensile tests was used in the FE model.
Critical locations (shown in red $^{1}$ ) are prone to mode-I fatigue cracks. The SCF calculated by FE modeling is 2.48 which is in a good agreement with one obtained by Fig. 3. The notch sensitivity factor in Table 1 for transverse hole is $\sqrt{a}=\frac{147}{S_{u t}}=0.31$, thus the notch sensitivity parameter as calculated using Eq. (12) is 0.92 , and the fatigue SCF calculated by Eq. (11) is 2.38 . The maximum stress at the edge of the hole $\sigma^{h}$ is written in term of remote stress $\left(\sigma^{\infty}\right)$ using Eq. (10) by:

$\sigma^{h}=k_{f} \frac{w}{w-d} \sigma^{\infty}=2.38\left(\frac{115}{115-23}\right) \sigma^{\infty}=2.975 \sigma^{\infty}$

\subsection{Test plan}

Four steel beams including one unstrengthened beam (B1), and three strengthened beams (B2, B3 and B4), as shown in Table 2, were subjected to cyclic loads till a fatigue crack is detected.

\subsubsection{Specimen $B 1$ (control specimen, no strengthening)}

Fatigue test 1 (B1F1) was performed on specimen B1 having no CFRP strengthening (intended as a control test). The control beam was subjected to a fatigue load range of $F=2.5-68 \mathrm{kN}$, as shown in Fig. 10. The stress level at the bottom flange of steel beam (far from the hole), was measured using the bonded strain gauge. Using Eq. (27), the minimum and maximum stress components at the location of the holes are calculated. Thus, the midrange and alternating stress components, calculated by Eqs. (1) and (2), are plotted in Fig. 11a (i.e., B1F1). Since the stress components are in the finite life region, it is expected that a macrocrack will be detected from the hole. As it has been mentioned earlier, detecting a macrocrack indicates that the crack initiation period is completed. Eddy current NDT system was used to inspect the near hole region to detect any possible crack. The fatigue test was stopped in intervals of about 100,000 cycles for an NDT inspection. A fatigue crack was detected at $N=600,000$ cycles and cyclic loading was stopped (see Table 2).

\subsubsection{Specimen $B 2$ (strengthened specimen)}

5.5.2.1. Fatigue test B2F1. Fatigue test 2 (B2F1) was performed on the second beam (specimen B2) containing pre-stressed CFRP strengthening. The beam was strengthened using the PUR system, shown in Fig. 8a. Fig. 12a shows the time-history of stresses in the CFRP plates and steel while increasing the eccentricity $e_{p}$. The

\footnotetext{
${ }^{1}$ For interpretation of color in Figs. 3 and 11, the reader is referred to the web version of this article.
} 
Table 2

The test matrix.

\begin{tabular}{|c|c|c|c|c|c|c|}
\hline Fatigue test name & Beam no. & Load range $(\mathrm{kN})$ & Applied no. of cycles & Strengthening scheme & Crack detected? & CFRP pre-stress level (\%) \\
\hline B1F1 & B1 & $2.5-68$ & 600,000 & Un-strengthened & Yes & - \\
\hline B2F1 & B2 & $2.5-68$ & $2,000,000$ & Strengthened & No & 30 \\
\hline B2F2 & B2 & $2.5-68$ & $4,000,000$ & Strengthened & No & 22 \\
\hline B2F3 & B2 & $2.5-68$ & $4,000,000$ & Strengthened & No & 14 \\
\hline B2F4 & B2 & $2.5-68$ & $1,500,000$ & Strengthened & Yes & 4 \\
\hline B3F1 & B3 & $2.5-68$ & $2,000,000$ & Strengthened & No & 30 \\
\hline B3F2 & B3 & $2.5-68$ & $4,000,000$ & Strengthened & No & 22 \\
\hline B3F3 & B3 & $2.5-68$ & $1,200,000$ & Strengthened & Yes & 14 \\
\hline B4F1 & B4 & $2.5-68$ & $8,000,000$ & Strengthened & No & 22 \\
\hline B4F2 & B4 & $2.5-68$ & $6,000,000$ & Strengthened & No & 14 \\
\hline B4F3 & B4 & $2.5-68$ & 900,000 & Strengthened & Yes & 4 \\
\hline
\end{tabular}

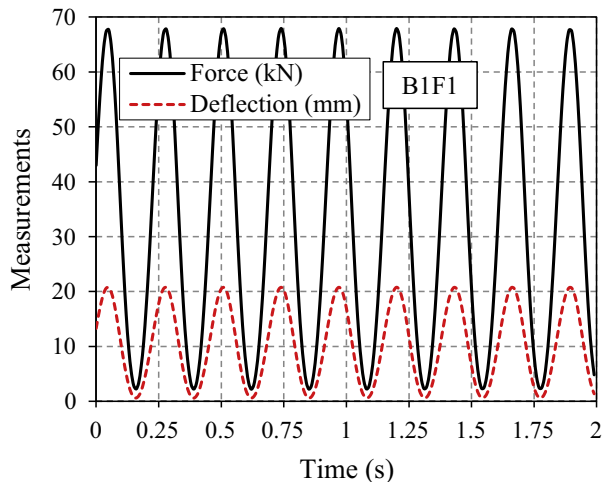

Fig. 10. The time-histories of the force and the deflection for fatigue test B1F1, specimen B1.

eccentricity between CFRP plate and beam bottom flange was increased to about $e_{p}=190 \mathrm{~mm}$, inducing a CFRP pre-stress equal to about $30 \%$ of the CFRP strength. At this pre-stress level, the maximum compressive stress at the hole in the flange reached $-211.7 \mathrm{MPa}$. After strengthening, the beam was subjected to a similar load range as the control beam (i.e., $F=2.5-68 \mathrm{kN}$ ). Fig. $11 \mathrm{~b}$ shows the time-histories of the hydraulic actuator force as well as stresses in the CFRP plates and steel. Points 1 and 2 in Fig. 11a indicate the critical stress components (at the hole location), in the CLD, before and after strengthening, respectively. The gray arrows in Fig. 11a illustrate how stresses are moving in the CLD diagram after strengthening at different CFRP pre-stress levels. In Fig. $11 \mathrm{a}$, the stress components shift into the safe region after strengthening, thereby an infinite fatigue life is expected. After $2,000,000$ cyclic loading cycles, no crack was detected (using the Eddy current system) near the holes in the flange. From Fig. 11a, with 30\% CFRP pre-stress, the alternating stress component decreased to some extent. The reason is that the cross-section dimensions of the beam are not significantly bigger than those of CFRP plates. Thus when the beam is strengthened with 30\% CFRP pre-stress, the stiffness of the system slightly increases (due to adding CFRP materials and also CFRP eccentricity).

5.5.2.2. Fatigue test B2F2. The CFRP eccentricity was decreased from $e_{p}=190 \mathrm{~mm}$ (corresponding to $30 \%$ CFRP pre-stress) to $e_{p}=172$ $\mathrm{mm}$ (corresponding to $22 \%$ CFRP pre-stress), resulting in a stress increase from $-211.7 \mathrm{MPa}$ to $-135.1 \mathrm{MPa}$ at the critical location of steel beam. The strengthened beam was then subjected to a similar load range as for control beam (i.e., $F=2.5-68 \mathrm{kN}$ ). Fig. $11 \mathrm{c}$ shows the variation of stresses in CFRP plates and steel beam and cyclic applied force. Note that compared to fatigue test B2F1, the level of applied external load (red curve in Fig. 11c) remained the same, the fluctuating stress in CFRP (blue curve in Fig. 11c) decreased, while the level of fluctuating stress in critical location of steel beam (black curve in Fig. 11c) increased. In general, as the pre-stress level decreases (due to smaller $e_{p}$ ), the stiffness of the system slightly drops, therefore $\sigma_{a}$ increases. Point 3 in Fig. 11a represents the location of the stress components (in the steel beam) after strengthening. The gray arrow indicates how the stresses in steel beam are transferred from point 2 to point 3 due to reduction of the CFRP pre-stress. The stress component has shifted almost on the modified Goodman line, thereby an infinite fatigue life is expected. The specimen survived 4,000,000 cyclic loadings, without any detectable macrocrack, as expected by the theory.

5.5.2.3. Fatigue test $B 2 F 3$. The CFRP eccentricity was decreased from $e_{p}=172 \mathrm{~mm}$ (corresponding to 22\% CFRP pre-stress) to $e_{p}=151.2$ $\mathrm{mm}$ (corresponding to $14 \%$ CFRP pre-stress), changing the stress at the critical location from $-135.1 \mathrm{MPa}$ to $-95.8 \mathrm{MPa}$. After prestressing was released to $14 \%$, the strengthened beam was subjected again to $F=2.5-68 \mathrm{kN}$, as shown in Fig. $11 \mathrm{~d}$. Note that the previous loading histories on specimen B2 (i.e., B2F1 and B2F2 tests) do not affect the current fatigue test. It is because an infinite fatigue life $(N=\infty)$ was estimated for both tests B2F1 and B2F2, which results in a negligible damage based on the Palmgren-Miner linear damage formulation. Point 4 in Fig. 11a represents the CLD location of the stress components after strengthening. The stress component has shifted to the region outside of modified Goodman line which is often called the risky region. The specimen survived $4,000,000$ cyclic loadings, and no fatigue crack was detected. The reason that specimen did not fail is due to that fact that the modified Goodman line is a conservative criterion for ductile metals.

5.5.2.4. Fatigue test B2F4. In the fourth fatigue test on specimen $\mathrm{B} 2$ (B2F4), the CFRP eccentricity was decreased again from $e_{p}=151.2$ $\mathrm{mm}$ (corresponding to $14 \%$ CFRP pre-stress) to $e_{p}=119.2 \mathrm{~mm}$ (corresponding to $4 \%$ CFRP pre-stress), again changing the stress at the critical location from $-95.8 \mathrm{MPa}$ to $-71.5 \mathrm{MPa}$, as shown in Fig. $12 \mathrm{~b}$. After pre-stressing was reduced to $4 \%$, the strengthened beam was subjected to $F=2.5-68 \mathrm{kN}$. Fig. 11e shows the variation of stresses in CFRP plates and steel beam. Point 5 (shown with a red marker) in Fig. 11a represents the CLD location of stress components (in the steel) after strengthening. Compared to the B2F3 test, the stress components in B2F4 test are closer to the Gerber curve which increases the possibility of detecting a fatigue macrocrack. Thus, more frequent NDT inspection was carried out during the fatigue test. Eventually, a fatigue crack was detected at $N=1,500,000$ cycles at hole location. Results of fatigue experiment on specimen B2 show that as long as the stress components in steel beam remained in the fatigue safe area determined by the 


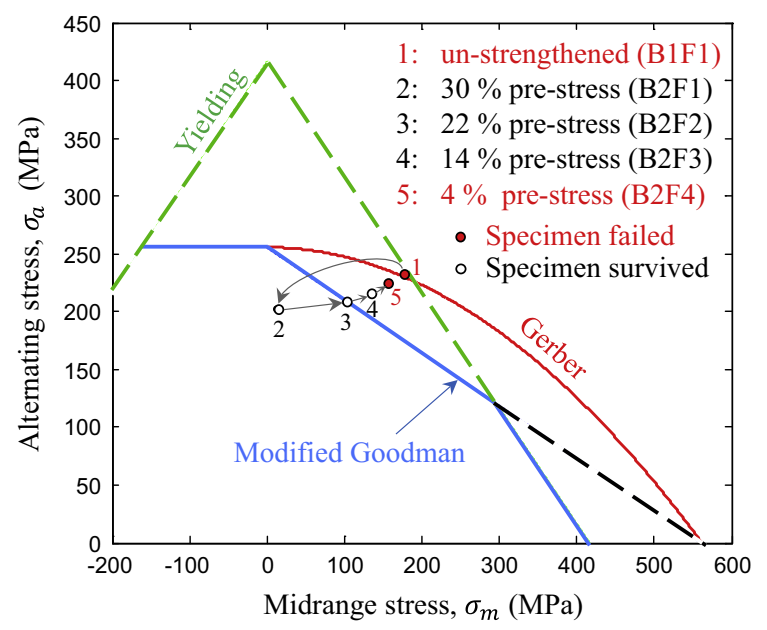

(a)

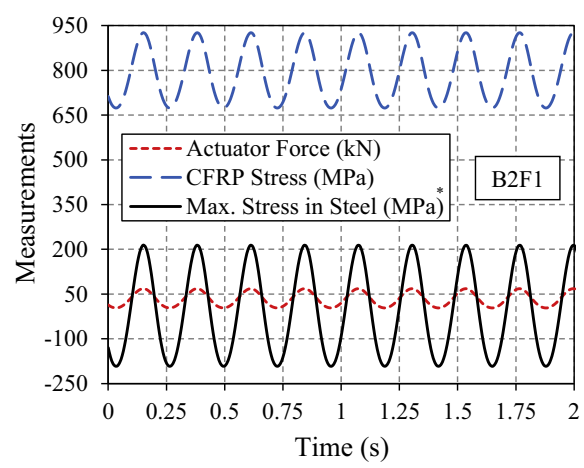

(b)

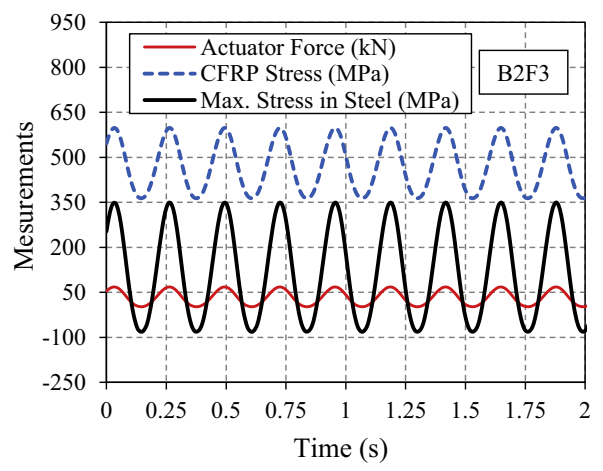

(d)

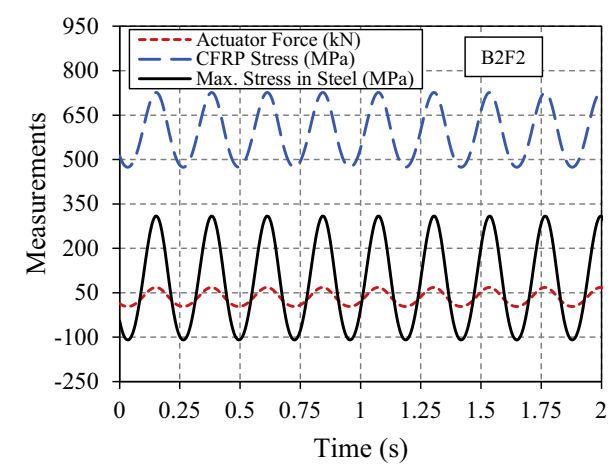

(c)

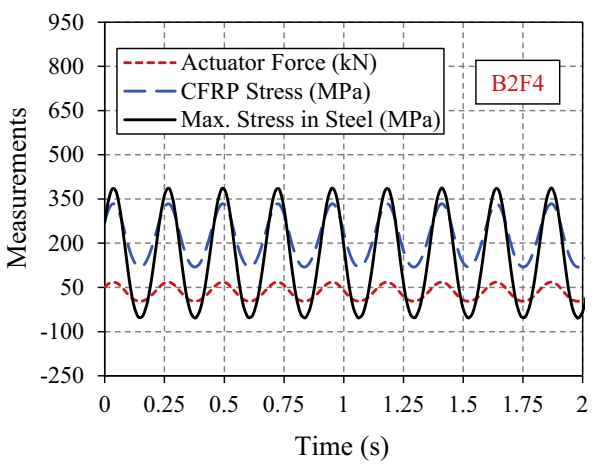

(e)

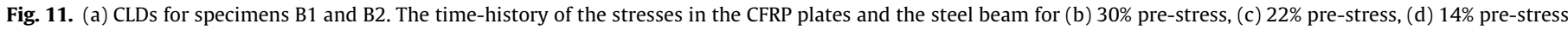
and (e) $4 \%$ pre-stress. * Maximum stress in steel refers to critical locations (i.e., at holes, see Fig. 9d).

modified Goodman line, infinite fatigue life was attained. Fatigue design based on the Gerber failure criterion is not conservative.

\subsubsection{Specimen $B 3$ (strengthened specimen)}

Due to inherent scatter in fatigue lives, specimen B3 was prepared and tested with an identical experimental procedure as described for specimen B2. Similar to specimen B2, specimen B3 was strengthened by the PUR system with $30 \%$ CFRP pre-stress and was subjected to $2,000,000$ cycles. Since no crack was detected, the pre-stress level was reduced to $22 \%$ and $4,000,000$ cycles were applied. No fatigue crack was identified. Again, the CFRP pre-stress level was decreased to $14 \%$ and after $1,200,000$ cycles, a fatigue crack was found at the hole location. The stress components for different pre-stress levels are illustrated in Fig. 13a. Results from fatigue test B3F3 show that the specimen cracked while its stress components were in the risky area outside the modified Goodman line. Nevertheless, the test with the same pre-stress level on specimen B2 (i.e., B2F3) survived, indicating the scatter results of fatigue tests. Fatigue tests on specimen $\mathrm{B} 3$ still show that the modified Goodman is conservative for design.

\subsubsection{Specimen $B 4$ (strengthened specimen)}

Fatigue tests were conducted on specimens B2 and B3 by strengthening starting with a high pre-stress level and reducing it stepwise. This type of testing procedure is often called 'modified staircase method' which is normally used to determine the fatigue 


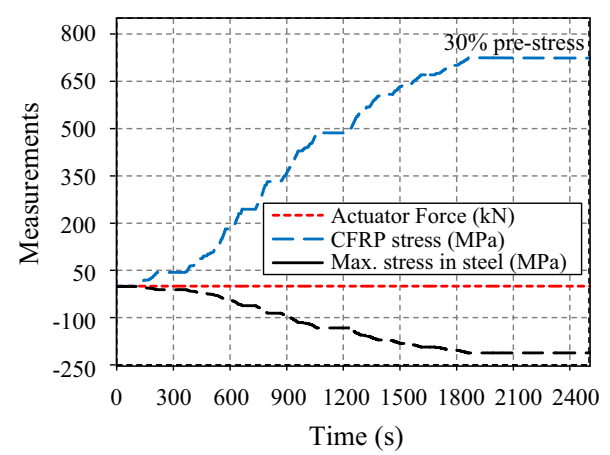

(a)

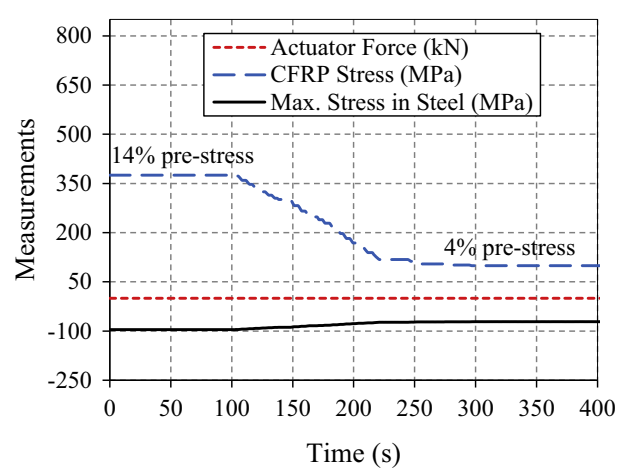

(b)

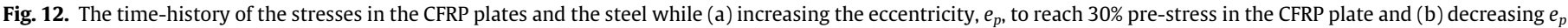
to release the CFRP pre-stress level from $14 \%$ to $4 \%$.

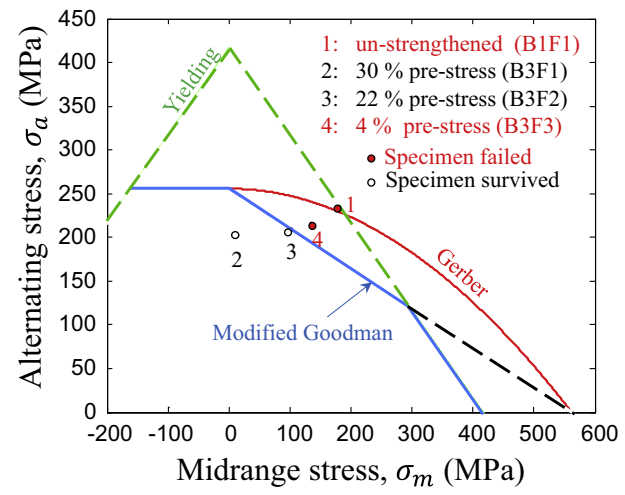

(a)

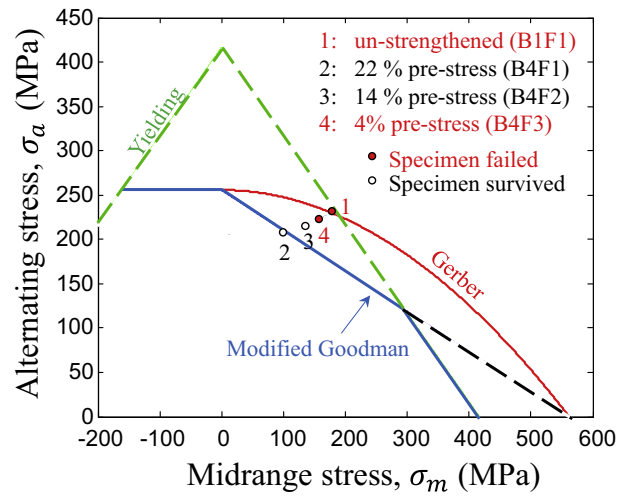

(b)

Fig. 13. Fatigue test results presented in the CLD diagrams for specimens (a) B1 and B3 and (b) B1 and B4.

strength of steels when a limited number of specimens are available. Although modified staircase is a well-known method in fatigue testing, some studies have shown the tendency to increase the fatigue strength in this testing method. This phenomena is the called 'training effect'. The training effect sometimes happens when a specimen is subjected to a stress level that is below its fatigue strength, and the stress level increases incrementally. In some cases, it tended to increase the actual fatigue strength. In order to check the possible influence of the training effect on results of conducted tests on specimens B2 and B3, specimen B4 was prepared identically as previous specimens; however, unlike specimens B2 and B3, specimen B4 was strengthened initially by $22 \%$ CFRP prestress (which is on the modified Goodman line). The specimen survived 8,000,000 cycles during the first fatigue test (B4F1). Following, the CFRP pre-stress level was decreased to $14 \%$ and the cyclic loading was restarted. The specimen survived $6,000,0000$ more cycles during B4F2 test. Once more, the CFRP pre-stress level was reduced to $4 \%$ and a fatigue crack was detected after 900,000 cycles at the hole location. Fig. 13b shows the stress components for different levels of pre-stress. Results from these fatigue tests do not reveal any training effect.

\subsection{Discussions on test results}

Fig. 14 summarizes the fatigue test results using the modified staircase method. In this figure, the pre-stress level in which the specimen failed is referred to as failure, while run-out indicates the last pre-stress level by which the specimen survived and,

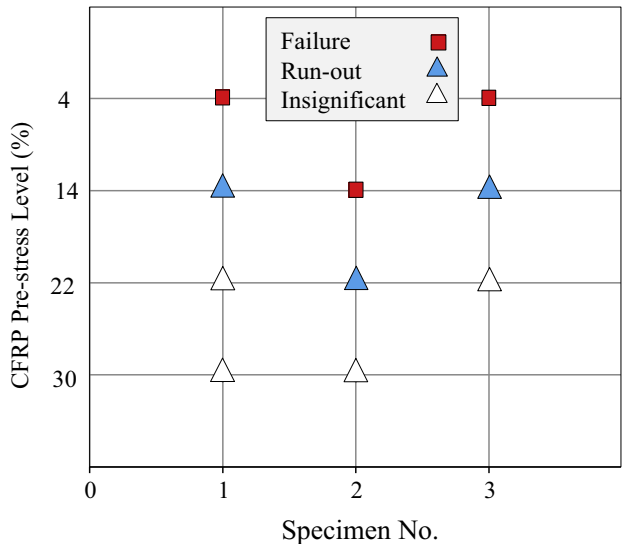

Fig. 14. Presentation of test results using the modified staircase method.

insignificant markers show the rest of lower pre-stress levels. The CFRP pre-stress level of $22 \%$ is found to be the minimum pre-stress that all specimens could have an infinite life. This prestress level corresponds to a stress component located on the modified Goodman line. Note that based on Eq. (26), the minimum required pre-stress level (with a safety factor of $n=1$ ) is calculated to be about $28 \%$, which is higher than $22 \%$ pre-stress level obtained from experiment. As mentioned earlier in deriving Eq. (26), it was assumed that the stiffness of the girder increases negligibly by strengthening. This conservative assumption is more realistic for 
strengthening of girders of existing large-scale bridges where typical cross-sectional dimensions are large relative to the CFRP dimensions. If high modulus CFRP plates are used, the alternating stress component is probably not negligible and may have to be considered.

All specimens tested herein were strengthened using the developed PUR system described previously. Only one pair of friction clamps was used for strengthening of all three specimens B2, B3 and B4. The high flexibility of the designed PUR system allowed easy modification of the pre-stress level several times for each specimen. The strengthening system survived a total of $33,000,000$ applied cycles on strengthened specimens. During the 33,000,000 cycles, slipping was not noticed between the CFRP plates and clamp, or between the clamp and steel flange, indicating excellent fatigue performance of the PUR system.

\section{Conclusions}

In this study, analytical formulations based on the CLD method were presented to predict the minimum required pre-stress level to prevent fatigue crack in existing metallic riveted bridges. A PUR system was developed and tested to validate optimum prestress levels determined from the analytical study. A total of four identical steel beams were tested, including one unstrengthened beam and three strengthened beams, in a modified staircase method. The following conclusions are determined from the analytical and experimental study:

- The minimum required pre-stress level determined from the CLD analysis corresponded well with observed experimental result. The minimum pre-stress calculated for the test specimens using the developed Eq. (26) from the modified Goodman CLD corresponds to nearly $28 \%$ the CFRP strength, which is slightly higher than $22 \%$ pre-stress level obtained from the modified staircase experimental testing. This pre-stress difference is likely associated with a conservative assumption made during the derivation of Eq. (26), which assumed negligible stiffness increase from the strengthening system. This assumption is more realistic for strengthening of large-scale bridge girders where typical cross-sectional dimensions are large relative to the CFRP dimensions.

- The proposed method can be used particularly for fatigue strengthening of metallic structures with unknown stress history from the past traffic loadings. The method can determine the required CFRP pre-stress, based on the stress history from the current traffic loadings on the bridge, to prevent fatigue crack cracking. Note that the strengthening can only be made after NDT inspection to ensure that there are no existing macrocracks. If such macrocracks are found, another method $[7,8]$, which is based on fracture mechanics, shall be used to determine the required CFRP pre-stress that can arrest the crack propagation.

- The developed PUR system performed well during the fatigue testing, surviving more than 33,000,000 cycles without any damage or sliding of the friction clamps. The pre-stress level with the PUR system was easily changed between multiple fatigue tests, indicating increased versatility over other bonded CFRP strengthening methods.

- The modified Goodman line presents a safe regime of cyclic loading for infinite fatigue life in ductile metals (such as wrought iron and structural carbon steels).

- Many structural design standards consider the stress range as the only parameter that affect the fatigue life of the metallic members, however the results of this study clearly show that reducing the mean stress level (with preserving the stress range) can transfer a member from finite fatigue-life regime to infinite fatigue-life regime. The presented CLD approach, in this paper, can reflect the combined effect of both the stress range and the mean stress and can be used for fatigue strengthening designs.

\section{Acknowledgments}

This study was funded by the Swiss Commission of Technology and Innovation (CTI) (Grant No. 12993.1 PFIW-IW). Financial and technological support from S\&P Clever Reinforcement AG Company and the Swiss Federal Railways (SBB) are also acknowledged. Furthermore, the authors would like to thank Prof. Xiao-Ling Zhao from Monash University, Australia, for his helpful comments on this study while he was visiting Empa.

\section{Appendix A}

Surface condition modification factor: the rotating-beam sample has a highly polished surface. A surface modification factor which is a function of tensile strength of the actual part and its quality of surface finish is written by [36]:

$k_{a}=a S_{u t}^{b}$

where $a$ and $b$ are two coefficients given in Table A.1.

Size modification factor: the size factor for round rotating bars has been obtained through curve fitting from many experimental data as [37]:

$k_{b}=\left\{\begin{array}{ll}1.24 d^{-0.107}, & 2.79 \leqslant d \leqslant 51 \mathrm{~mm} \\ 1.51 d^{-0.157}, & 51<d \leqslant 254 \mathrm{~mm}\end{array}\right.$.

The size factor presented in the above equation is for the case of rotating bars. For structural members (that often do not rotate) and have a non-tubular section, the method of effective dimension is used. The effective dimension $d_{e}$ is calculated by equating the area of stressed at $95 \%\left(A_{0.95 \sigma}\right)$ of maximum stress to the same area in the rotating-beam samples [38]. Fig. A.1 shows $A_{0.95 \sigma}$ and the corresponding effective dimension $d_{e}$ for rectangular and I-beam cross-sections. Once $d_{e}$ is calculated, it can be used in Eq. (A.2) to

Table A.1

Surface coefficients for different levels of the surface finish [32].

\begin{tabular}{lll}
\hline Surface finish & Exponent $b$ & Factor $a S_{u t}(\mathrm{MPa})$ \\
\hline As-forged & -0.995 & 272 \\
Hot-rolled & -0.718 & 57.7 \\
Machined/cold-drawn & -0.265 & 4.51 \\
Ground & -0.085 & 1.58 \\
\hline
\end{tabular}
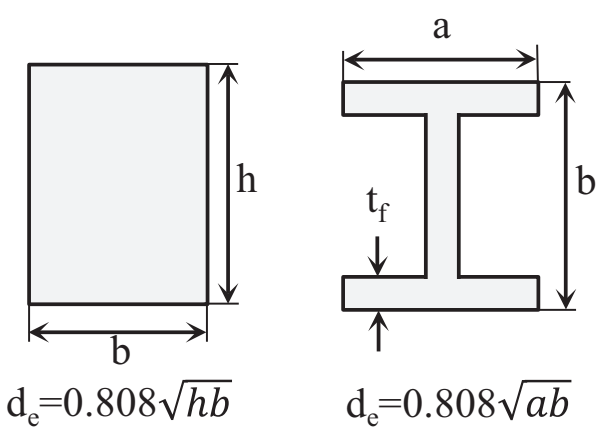

Fig. A.1. Effective dimension, $d_{e}$, for rectangular and I-beam cross-sections [34]. 
Table A.2

Reliability factors based on probabilistic analysis with Gaussian distribution assumption [36].

\begin{tabular}{lll}
\hline Reliability (\%) & $z_{a}$ & $k_{e}$ \\
\hline 50 & 0 & 1.000 \\
90 & 1.288 & 0.897 \\
95 & 1.645 & 0.868 \\
99 & 2.326 & 0.814 \\
99.9 & 3.091 & 0.753 \\
99.99 & 3.719 & 0.702 \\
\hline
\end{tabular}

find the right size factor. Note that for axial loading, the size factor is $k_{b}=1$.

Load modification factor: results of obtained endurance limits are different if tests are carried out with rotating bending, axial (tension-compression) or torsion and are estimated by [21]:

$k_{c}=\left\{\begin{array}{ll}1, & \text { bending } \\ 0.85, & \text { axial } \\ 0.59, & \text { torsion }\end{array}\right.$ for steel and wrought iron. 0.9 .

The average $k_{c}$ for axial and torsional loading for cast irons is

Temperature modification factor: experimental results have shown that if operating temperature is much higher or lower than room temperature, yielding or brittle failure, respectively, shall be the first investigated [21]. The following fourth order polynomial, which has been obtained by fitting to the experimental results at different operation temperature, can be used to determine the temperature factor as [39]:

$$
\begin{aligned}
k_{d}= & 0.9877+0.6507\left(10^{-3}\right) T_{c}-0.3414\left(10^{-5}\right) T_{c}^{2} \\
& +0.5621\left(10^{-8}\right) T_{c}^{3}-6.246\left(10^{-12}\right) T_{c}^{4},
\end{aligned}
$$

where $T_{c}$ is the temperature in degree Celsius.

Reliability modification factor: as was mentioned earlier, the presented modification factors have been calculated through a statistical analysis where data have been very scatter but reported as mean values. A relation for standard deviation of endurance strengths has been presented by [40] as:

$k_{e}=1-0.08 z_{a}$,

where $z_{a}$ is defined through a probabilistic analysis with Gaussian distribution assumption and is shown in Table A.2. The table also includes the corresponding reliability factors for each $z_{a}$. Since the data were reported as mean values of several experiments, it is evident that $50 \%$ reliability results in $k_{e}=1$.

\section{References}

[1] Schijve J. Fatigue of structures and materials. New York: Springer; 2008.

[2] Ghafoori E, Prinz GS, Mayor E, Nussbaumer A, Motavalli M, Herwig A, et al. Finite element analysis for fatigue damage reduction in metallic riveted bridges using pre-stressed CFRP plates. Polymers 2014;6(4):1096-118.

[3] Ghafoori E, Motavalli M. Flexural and interfacial behavior of metallic beams strengthened by prestressed bonded plates. Compos Struct 2013:22-34.

[4] Ghafoori E. Interfacial stresses in beams strengthened with bonded prestressed plates. Eng Struct 2012:508-10.

[5] Colombi P, Bassetti A, Nussbaumer A. Crack growth induced delamination on steel members reinforced by prestressed composite patch. Fatigue Fract Eng Mater Struct 2003;26(5):429-37.

[6] Ghafoori E, Motavalli M. Analytical calculation of stress intensity factor of cracked steel I-beams with experimental analysis and 3D digital image correlation measurements. Eng Fract Mech 2011:3226-42.

[7] Ghafoori E, Motavalli M, Botsis J, Herwig A, Galli M. Fatigue strengthening of damaged metallic beams using prestressed unbonded and bonded CFRP plates. Int J Fatigue 2012;44:303-15.
[8] Ghafoori E, Schumacher A, Motavalli M. Fatigue behavior of notched steel beams reinforced with bonded CFRP plates: determination of prestressing level for crack arrest. Eng Struct 2012;45:270-83.

[9] Huawen Y, König C, Ummenhofer T, Shizhong Q, Plum R. Fatigue performance of tension steel plates strengthened with prestressed CFRP laminates. J Compos Constr 2010;14(5):609-15.

[10] Täljsten B, Hansen CS, Schmidt JW. Strengthening of old metallic structures in fatigue with prestressed and non-prestressed CFRP laminates. Constr Build Mater 2009:1665-77.

[11] Wang R, Nussbaumer A. Modelling fatigue crack propagation of a cracked metallic member reinforced by composite patches. Eng Fract Mech 2009;76:1277-87. http://dx.doi.org/10.1016/j.engfracmech.2009.02.004.

[12] Wu C, Zhao XL, Al-Mahaidi R, Emdad MR, Duan WH. Fatigue tests on steel plates with longitudinal weld attachment strengthened by ultra high modulus carbon fibre reinforced polymer plate. Fatigue Fract Eng Mater Struct 2013; 36(10):1027-38.

[13] Wu C, Zhao XL, Chiu WK, Al-Mahaidi R, Duan WH. Effect of fatigue loading on the bond behaviour between UHM CFRP plates and steel plates. Compos B Eng 2013:50:344-53.

[14] Park S, Kim T, Kim K, Hong S-N. Flexural behavior of steel I-beam prestressed with externally unbonded tendons. J Constr Steel Res 2010;66(1):125-32.

[15] Troitsky MS. Prestressed steel bridges. New York: Van Nostrand Co.; 1990.

[16] Al-Emrani M, Kliger R. Experimental and numerical investigation of the behaviour and strength of composite steel-CFRP members. Adv Struct Eng 2006;9(6):819-31.

[17] Czaderski C, Rabinovitch O. Structural behavior and inter-layer displacements in CFRP plated steel beams - optical measurements, analysis, and comparative verification. Composites B 2010:276-86.

[18] Haghani R, Al-Emrani M, Kliger R. Interfacial stress analysis of geometrically modified adhesive joints in steel beams strengthened with FRP laminates. Constr Build Mater 2009:1413-22.

[19] Zhao XL, Bai Y, Al-Mahaidi R, Rizkalla S. Effect of dynamic loading and environmental conditions on the bond between CFRP and steel: state-of-theart review. J Compos Constr 2014;18(3).

[20] Ghafoori E, Motavalli M, Nussbaumer A, Herwig A, Prinz GS, Fontana M. Design criterion for fatigue strengthening of riveted beams in a 120-year-old railway metallic bridge using pre-stressed CFRP plates. Composites B 2015;68:1-13.

[21] Budynas RG, Nisbett JK. Shigley's mechanical engineering design. New York: McGraw-Hill; 2008.

[22] Klubberg F, Klopfer I, Broeckmann C, Berchtold R, Beiss P. Fatigue testing of materials and components under mean load conditions. Ann Fract Mech 2011; 28(1):419-24.

[23] Marin J. Mechanical behavior of engineering materials. Englewood Cliffs: Prentice-Hall; 1962.

[24] Sines G, Waisman JL. Metal fatigue. New York: McGraw-Hill; 1969. Copyright 1969 by the McGraw-Hill Companies Inc.

[25] Brühwiler E, Smith I, Hirt M. Fatigue and fracture of riveted bridge members. J Struct Eng 1990;116(1).

[26] Helmerich R, Brandes K, Herter J. Full scale laboratory fatigue tests on riveted railway bridges. Evaluation of existing steel and composite bridges. IABS workshop, Lausanne; 1997. p. 191-200.

[27] Larsson T. Material and fatigue properties of old metal bridges. Luleå University of Technology, licentiate thesis; 2006.

[28] Cadei J, Stanford T, Hollaway L, Duckett W. Strengthening metallic structures using externally bonded fibre-reinforced polymers. London: CIRIA; 2004. C595.

[29] van Maarschalkerwaart $H$. Fatigue behaviour of riveted joints. IABSE Colloquium, Lausanne; 1982. p. 691-8.

[30] Akesson B. Fatigue life of riveted railway bridges. Chalmers University of Technology, Sweden. PhD Thesis; 1994.

[31] Yin W, Fang Q, Wang S, Wang X. Fatigue strength of high-strength bolted joints. IABSE Colloquium, Lausanne; 1982. p. 707-14.

[32] Manson SS, Nachtigall AJ, Rnsign CR, Fresche JC. Further investigation of a relation for cumulative fatigue damage in bending. Trans ASME J Eng Ind Ser B 1965:87(1):25-35.

[33] Collins JA. Failure of materials in mechanical design. New York: John Wiley \& Sons; 1981. 243.

[34] Ghafoori E, Motavalli M. Verfahren zum Vorspannen eines Stahlbauwerkes sowie damit vorgespanntes Stahbauwerk. Swiss Patent, CH 706630 B1, 14th May; 2013

[35] Ghafoori E, Motavalli M. Innovative CFRP pre-stressing system for strengthening of metallic structures. J Compos Constr (submitted for publication).

[36] Noll CJ, Lipson C. Allowable working stress, society for experimental stress analysis. Soc Exp Stress Anal 1946;3(2):29.

[37] Mischke CR. Prediction of stochastic endurance strength. Trans ASME J Vibr Acoust Stress Reliab Des 1987;109(1).

[38] Kiguel R. A relation between theoretical stress concentration factor and fatigue notch factor deduced from the concept of highly stressed volume. ASTM Proc $1961 ; 61: 73-748$

[39] Brandes EA. Smithells metal reference book. 6th ed. London: Butterworth; 1983.

[40] Haugen EB, Wirsching PH. Probabilistic design. Mach Des 1975;47(12):10-4. 